\title{
Evaluation of Vapor Pressure Estimation Methods for Use in Simulating the Dynamic of Atmospheric Organic Aerosols
}

\author{
A. J. Komkoua Mbienda, ${ }^{1}$ C. Tchawoua, ${ }^{2}$ D. A. Vondou, ${ }^{1}$ and F. Mkankam Kamga ${ }^{1}$ \\ ${ }^{1}$ Laboratory of Environmental Modeling and Atmospheric Physics, Department of Physics, Faculty of Science, University of Yaounde 1, \\ P.O. Box 812, Yaounde, Cameroon \\ ${ }^{2}$ Laboratory of Mechanics, Department of Physics, Faculty of Science, University of Yaounde 1, P.O. Box 812, Yaounde, Cameroon
}

Correspondence should be addressed to A. J. Komkoua Mbienda; kombiend@gmail.com

Received 24 March 2013; Accepted 5 June 2013

Academic Editor: Robert Tenzer

Copyright (C) 2013 A. J. Komkoua Mbienda et al. This is an open access article distributed under the Creative Commons Attribution License, which permits unrestricted use, distribution, and reproduction in any medium, provided the original work is properly cited.

\begin{abstract}
The modified Mackay (mM), the Grain-Watson (GW), Myrdal and Yalkovsky (MY), Lee and Kesler (LK), and Ambrose-Walton (AW) methods for estimating vapor pressures $\left(P^{\text {vap }}\right)$ are tested against experimental data for a set of volatile organic compounds (VOC). $P^{\text {vap }}$ required to determine gas-particle partitioning of such organic compounds is used as a parameter for simulating the dynamic of atmospheric aerosols. Here, we use the structure-property relationships of VOC to estimate $P^{\text {vap }}$. The accuracy of each of the aforementioned methods is also assessed for each class of compounds (hydrocarbons, monofunctionalized, difunctionalized, and tri- and more functionalized volatile organic species). It is found that the best method for each VOC depends on its functionality.
\end{abstract}

\section{Introduction}

Atmospheric aerosols (AA) have a strong influence on the earth's energy balance [1] and a great importance in the understanding of climate change and human health (respiratory and cardiac diseases, cancer). They are complex mixtures of inorganic and organic compounds, with composition varying over the size range from a few nanometers to several micrometers. Given this complexity and the desire to control AA concentration, models that accurately describe the important processes that affect size distribution are crucial. Therefore, the representation of particle size distribution is of interest in aerosol dynamics modeling. However, in spite of the impressive advances in the recent years, our knowledge of AA and physical and chemical processes in which they participate is still very limited, compared to the gas phase [2]. Several models have been developed that include a very thorough treatment of AA processes such as in Adams and Seinfeld [3], Gons et al. [4], and Whitby and McMurry [5]. Indeed, the evolution of size distribution of AA is made by a mathematical formulation of processes called the general dynamic equation (GDE). It is well known that the first step in developing a numerical aerosol model is to assemble expressions for the relevant physical processes. The second step is to approximate the particle size distribution with a mathematical size distribution function. Thus, the time evolution of the particle size distribution of aerosols undergoing coagulation, deposition, nucleation, and condensation/evaporation phenomena is finally governed by GDE [1]. This latter phenomenon is characterized by the mass flux $I_{i}$ for volatile species $i$ between gas phase and particle which is computed using the following expression [6]:

$$
I_{i}=\frac{d m_{i}}{d t}=2 \pi D_{i}^{g} d_{p} f_{\mathrm{FS}}\left(K_{n_{i}}, \alpha_{i}\right)\left(c_{i}^{g}-c_{i}^{s}\right) .
$$

$f_{\mathrm{FS}}$ describes the noncontinuous effects [7]. When $I_{i} \geq$ $0\left(I_{i} \leq 0\right)$, there is condensation (evaporation). $c_{i}^{s}$ is assumed to be at local thermodynamic equilibrium with the particle composition [8] and can be obtained from the vapour pressure $\left(P_{i}^{\text {vap }}\right)$ of each volatile compound $i$ with average molar mass of the atmospheric aerosol, mole fraction, and activity coefficient, through the following equation:

$$
c_{i}^{s}=x \frac{\gamma P_{i}^{\mathrm{vap}} m 10^{6}}{R T},
$$

where $P_{i}^{\text {vap }}$ is given by the Clausius-Clapeyron law:

$$
P_{i}^{\text {vap }}(T)=P_{i}^{\text {vap }}(298) \exp ^{\left[-\left(H_{\text {vap }} / R\right)((1 / T)-(1 / 298))\right]} .
$$


Parameters in (1)-(3) are named in Table 1.

In (3), $H_{\text {vap }}$ is equal to $156 \mathrm{~kJ} / \mathrm{mol}$ as stated by Derby et al. [8]. Consequently, the vapour pressures of all aerosol compounds are needed to calculate the mass flux of condensing and evaporating compounds. The knowledge of $P_{i}^{\mathrm{vap}}$ for organic compound $i$ at the atmospheric temperature $T$ is required whenever phase equilibrium between gas phase and particle is of interest. Often, most of the compounds able to condense have experimental vapor pressures unavailable, and because of that, their estimation becomes necessary. To solve this problem of estimation, many methods have been developed. For example, in Tong et al. [9], a method based on atomic simulation is applied only for compounds bearing acid moieties. Quantum-mechanical calculations are making steady effort in vapor pressure prediction (Banerjee et al. [10]; Diedenhofen et al. [11]). Furthermore, current models describing gas-particle partitioning use semiempirical methods for vapor pressure estimation based on molecular structure, often in the form of a group contribution approach. Therefore, these methods require in most cases molecular structures (e.g., boiling point $T_{b}$, critical temperature $T_{c}$, and critical pressure $P_{c}$ ), which usually have themselves to be estimated. For example, The MY method [12] was used by Griffin et al. [13] and Pun et al. [14] for modeling the formation of secondary organic aerosol. Jenkin [15], in a gas particle partitioning model, used the modified form of the Mackay method [16]. Some methods (Pankow and Asher [17], Capouet and Müller [18]) assume a linear logarithmic dependence $\left(\ln P_{i}^{\mathrm{vap}}\right)$ on several functional groups, but this consideration fails when multiple hydrogen bonding groups are present. Furthermore, more investigations are needed to clarify which method can give values closer to the experimental data. Camredon and Aumont [19], Compernolle et al. [20], and Barley and McFiggans [21] have made an assessment of different vapor pressure estimation methods with experimental data for compounds of relatively higher volatility. For this latter reason, large differences in the estimated vapor pressure have been reported.

In this paper, our focus will be on the (i) evaluation of a number of vapor pressure estimation methods against experimental data using all volatile organic compounds present in our database and (ii) assessment of the accuracy of each of these methods on the base of each class of compounds.

The rest of the paper is organized as follows. In Section 2, we describe experimental data and methods. The results are presented in Section 3. Finally, we summarize our finding in Section 4.

\section{Data and Vapor Pressure Estimation Methods}

2.1. Experimental Data. The molecules selected in this study have been identified during in situ campaigns [22] and during chamber experiments [23]. In fact, they are hydrocarbons, monofunctionalized and multifunctionalized species, and bearing alcohol, aldehyde, ketone, carboxylic acid, ester, ether, and alkyl nitrate functions. The experimental vapor pressures are taken from NIST chemistry
TABLE 1: Nomenclature.

\begin{tabular}{ll}
\hline Parameters & Names \\
\hline$I_{i}$ & Mass flux for volatile species $i$ \\
$d_{p}$ & The particle wet diameter \\
$m_{i}$ & Mass of species $i$ \\
$D_{i}^{g}$ & Molar diffusivity in the air of species $i$ \\
$c_{i}^{g}$ & Gas-phase concentration of species $i$ \\
$f_{\mathrm{FS}}$ & Fuchs-Sutugin function \\
$c_{i}^{s}$ & Concentration at the surface of species $i$ \\
$R$ & Gas constant \\
$T$ & Temperature in Kelvin \\
$H_{\text {vap }}$ & Vaporisation enthalpy \\
$x$ & Mole fraction \\
$\gamma$ & Activity coefficient \\
$P_{i}^{\text {vap }}$ & Vapour pressure of each volatile compound $i$ \\
\hline
\end{tabular}

website (http://www.nist.gov/chemestry) and from Myrdal and Yalkowsky [12], Asher et al. [24], Lide [25], Yams [26], and Boulik et al. [27], and they have a range from $10^{-8} \mathrm{~atm}$ to $1 \mathrm{~atm}$. Molecular properties (boiling point, critical temperature, and critical pressure) are also taken from the NIST chemistry website. All vapor pressure estimation methods used in this study take into account these properties. In most cases, these properties have also to be estimated.

\subsection{Estimation of Molecular Properties}

2.2.1. Boiling Temperature $T_{b}$. Using the boiling temperature of Joback [28] and its extension, the group contribution technique denoted by $T_{b}^{\mathrm{Job}}$ is written as

$$
T_{b}^{\mathrm{Job}}=198+\sum_{i} N_{i} t_{b i}
$$

where $t_{b i}$ is the contribution of group $i$, and $N_{i}$ is the occurrence of this group in the molecule. As in Camredon and Aumont [19], the extension is made by adding some other group contribution to take into account molecules bearing hydroperoxide moiety $(-\mathrm{OOH})$, alkyl nitrate moiety $\left(\mathrm{ONO}_{2}\right)$, and peroxyacyl nitrate moiety $\left(-\mathrm{C}(=\mathrm{O}) \mathrm{OONO}_{2}\right)$. Thus, the first group is divided into the existing Joback groups -Oand $-\mathrm{OH}$. The second group value is provided by the NIST chemistry website, and the last group value is provided by Camredon and Aumont [19] using boiling point value from Bruckmann and Willner [29].

2.2.2. Critical Temperature $T_{c}$. We have used Joback [28] and Lydersen's [30] techniques to estimate $T_{c}$. Denoting by $T_{C}^{\mathrm{Job}}$ and $T_{c}^{\mathrm{Lyd}}$ the Joback and Lydersen critical temperatures, respectively, we have

$$
\begin{gathered}
T_{c}^{\mathrm{Job}}=\frac{T_{b}}{0,584+0,965 \sum_{i} N_{i} t_{i}-\left(\sum_{i} N_{i} t_{i}\right)^{2}}, \\
T_{c}^{\mathrm{Lyd}}=\frac{T_{b}}{0,567+\sum_{i} N_{i} t_{i}-\left(\sum_{i} N_{i} t_{i}\right)^{2}} .
\end{gathered}
$$


New group contributions have been added by Camredon and Aumont [19] for hydroperoxide, alkyl nitrate, and peroxyacyl nitrate moieties:

$$
\begin{gathered}
t_{c}^{-\mathrm{OOH}}=t_{c}^{-\mathrm{O}-}+t_{c}^{-\mathrm{OH}}, \\
t_{c}^{-\mathrm{ONO}_{2}}=t_{c}^{-\mathrm{O}-}+t_{c}^{-\mathrm{NO}_{2}}, \\
t_{c}^{-\mathrm{C}(=\mathrm{O}) \mathrm{OONO}_{2}}=t_{c}^{-\mathrm{C}(=\mathrm{O}) \mathrm{O}}+t_{c}^{-\mathrm{O}-}+t_{c}^{-\mathrm{NO}_{2}} .
\end{gathered}
$$

2.2.3. Critical Pressure $P_{c}$. The two techniques listed in the previous section have been used to estimate critical pressure $P_{c}$. Here, it is also assumed that $P_{c}$ is the sum of group contributions. Therefore, denoting by $P_{c}^{\text {Job }}$ and $P_{c}^{\text {Lyd }}$ the Joback and Lydersen critical pressures, respectively, we can write

$$
\begin{aligned}
& P_{c}^{\mathrm{Job}}= \frac{1}{\left(0,113+0,0032 n-\sum_{i} N_{i} p_{i}\right)^{2}}, \\
& P_{c}^{\mathrm{Lyd}}=\frac{M}{\left(0,34-\sum_{i} N_{i} p_{i}\right)^{2}}
\end{aligned}
$$

where $M$ is the molar mass, $n$ is the number of atoms in the molecule, and $p_{i}$ is the critical pressure contribution of group $i$. The new group contributions described in the previous subsection are taken into account here.

2.3. Vapor Pressure Estimation Methods. As said earlier, many methods for vapor pressure estimation have been developed and are based on the Antoine or on the extended form of the Clausius-Clapeyron equation. Let us present in what follows each of the five methods used.

2.3.1. The Myrdal and Yalkowsky (MY) Method. The MY method [12] starts from the extended form of the ClausiusClapeyron equation obtained by using Euler's cyclic relation. Here, the expression of $P^{\text {vap }}$ is given by

$$
\ln P^{\mathrm{vap}}=\frac{\Delta S_{b}\left(T_{b}-T\right)}{R T}+\frac{\Delta C_{p b}}{R}\left(\frac{T_{b}-T}{T}-\ln \frac{T_{b}}{T}\right)
$$

where $\Delta S_{b}$ is the vaporization entropy at the boiling temperature, $C_{p b}$ is the gas-liquid heat capacity, and $R$ is the gas constant. $\Delta S_{b}$ used in this method is an empirical expression given by Myrdal et al. [31]:

$$
\Delta S_{b}=86+0.4 \tau+1421 \mathrm{HBN} .
$$

In (9), the parameters $\tau$ and HBN which characterize the molecular structure represent the torsional bond (see Vidal [32]) and the hydrogen bonding number (see [19, Section 3.1.2]), respectively. $\Delta C_{p b}$ is a linear dependence of $\tau$ [32]:

$$
\Delta C_{p b}=-(90+2.5 \tau) .
$$

Thus, in the MY method, vapor pressure is estimated by the relatively simplified formula

$$
\begin{aligned}
\ln P^{\text {vap }}= & -(21,2+0,3 \tau+177 \mathrm{HBN})\left(\frac{T_{b}-T}{T}\right) \\
& +(10,8+0,25 \tau) \ln \frac{T_{b}}{T} .
\end{aligned}
$$

2.3.2. The Modified Mackay ( $m M$ ) Method. Often called simplified expression of Baum [33], this method is also based on the extended form of the Clausius-Clapeyron equation. The simplifying assumption here is to consider the ratio $\Delta C_{p b} / \Delta S_{b}$ to be constant [34]:

$$
\frac{\Delta C_{p b}}{\Delta S_{b}}=-0.8
$$

In (12), the vaporization entropy, $\Delta S_{b}$, takes into account the van der Waals interactions and is based upon the Trouton's rule. For its calculation, Lyman [35] has suggested the following expression:

$$
\Delta S_{b}\left(T_{b}\right)=K_{f}\left(36,6+8,31 \ln T_{b}\right),
$$

where $K_{f}$ is a structural factor of Fishtine [36] which corrects many polar interactions. It has different values as follows:

(i) $K_{f}=1$ for nonpolar and monopolar compounds;

(ii) $K_{f}=1.04$ for compounds with a weak bipolar character;

(iii) $K_{f}=1.1$ for primary amines;

(iv) $K_{f}=1.3$ for aliphatic alcohols.

Finally, the mM method is reduced to the following equation:

$$
\ln P^{\text {vap }}=K_{f}\left(4,4+\ln T_{b}\right)\left(1,8 \frac{T_{b}-T}{T}-0,8 \ln \frac{T_{b}}{T}\right) .
$$

2.3.3. The Grain-Watson (GW) Method. The GW method is based on the following equation [37]:

$$
\ln P^{\text {vap }}=\frac{\Delta S}{R}\left[1-\frac{\left(3-2 T_{p}\right)^{m}}{T_{p}}-2 m\left(3-2 T_{p}\right)^{m-1} \cdot \ln T_{p}\right] \text {, }
$$

where $m=0.4133-0.2575 T_{p}$ and $T_{p}$ is inversely proportional to $T_{b}\left(T_{p}=T / T_{b}\right) . \Delta S$ has the same form like that used in the mM method.

2.3.4. The Lee and Kesler (LK) Method. Like the methods described previously, the LK method required critical temperature, critical pressure, and boiling temperature. Here, the vapor pressure is estimated on the base of Pitzer expansion [38]:

$$
\ln P_{r}^{\mathrm{vap}}=f^{0}\left(T_{r}\right)+w f^{1}\left(T_{r}\right)
$$


where $P_{r}^{\text {vap }}$ is reduced vapor pressure, $T_{r}$ is reduced temperature, and $w$ is the Pitzer's acentric factor which accounts for the nonsphericity of molecules:

$$
w=\frac{-\ln P_{c}-f^{0}(\theta)}{f^{1}(\theta)}
$$

with $\theta=T_{b} / T_{c}$. In (16) and (17), $f^{0}$ and $f^{1}$ are the Pitzer's functions which are polynomials in $T_{r}$. Lee and Kesler have suggested the following equations [39]:

$$
\begin{aligned}
f^{0}\left(T_{r}\right)= & 5,92714-\frac{6.09648}{T_{r}} \\
& -1.28862 \ln T_{r}+0.169347 \ln T_{r}^{6}, \\
f^{1}\left(T_{r}\right)= & 15.2518-\frac{15.6875}{T_{r}} \\
& -13.4721 \ln T_{r}+0.43577 \ln T_{r}^{6} .
\end{aligned}
$$

2.3.5. The Ambrose-Walton (AW) Method. AW method [40] is also based on the Pitzer expansion. They have reported their analytical expressions of Pitzer's functions in the form of a Wagner type of vapor pressure equation:

$$
\begin{aligned}
& f^{0}\left(T_{r}\right) \\
& =\frac{-5.9761 \tau+1.29874 \tau^{1.5}-0.60394 \tau^{2.5}-1.06841 \tau^{5}}{T_{r}}, \\
& f^{1}\left(T_{r}\right) \\
& =\frac{-5.03365 \tau+1.11505 \tau^{1.5}-5.41217 \tau^{2.5}-7.46628 \tau^{5}}{T_{r}} .
\end{aligned}
$$

In (19), $\tau=1-T_{r}$.

\section{Results}

3.1. Molecular Properties. We present in this section the results obtained for the Joback and Lydersen techniques described previously. The accuracy of each of the five vapor pressure estimation methods used in this study is assessed taking into account the reliability of pure substance property estimates. The reliability of the two techniques presented in Section 2.2 is therefore crucial.

In Figure 1, where the results of Joback technique are displayed, $T_{b}^{\mathrm{Job}}$ is plotted against experimental values for a set of 253 volatile organic compounds. The scatter tends to be larger for boiling temperature higher than $500 \mathrm{~K}$. The correlation coefficient $\left(R^{2}=0.97\right)$ shows that estimated values match very well experimental $T_{b}$. The root mean square error (RMSE) and the mean absolute error (MAE) are, respectively, $17.60 \mathrm{~K}$ and $12.65 \mathrm{~K}$. This MAE agrees with $12.9 \mathrm{~K}$ and $12.1 \mathrm{~K}$ calculated in Reid et al. [39] and Camredon and Aumont [19] for a set of 252 and 438 volatile organic compounds, respectively. Hence, these results show that $T_{b}^{\mathrm{Job}}$

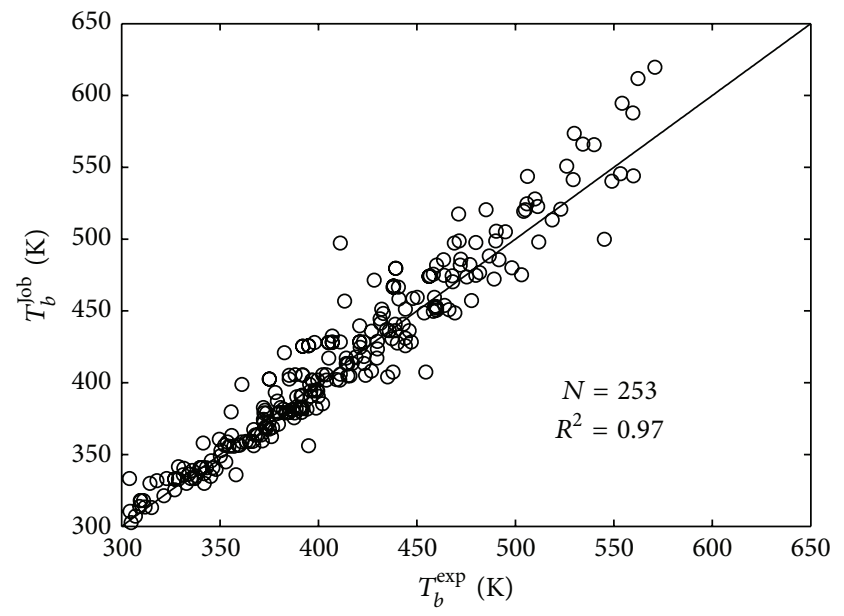

FIGURE 1: Estimated boiling point for a set of 253 species versus experimental values for the Joback technique. The black line is the $1: 1$ diagonal.

can be used in vapor pressure estimation methods. Moreover, Joback reevaluated Lydersen's group contribution scheme. $\mathrm{He}$ added several new functional groups and deducted new contribution values.

The two techniques for the estimation of $T_{c}$ are compared to experimental data of 138 compounds in Figure 2.

Figures 2(a) and 2(b) show that the Joback and Lydersen techniques give similar results for $T_{c}$ values lower than $700 \mathrm{~K}$. Joback technique shows a negative bias for $T_{c}$ higher than $700 \mathrm{~K}$. This technique gives for the overall compounds an RMSE of $24.98 \mathrm{~K}$. This value is higher than the $19.81 \mathrm{~K}$ provided by the Lydersen technique. The mean bias error (MBE) for $T_{c}^{\mathrm{Job}}$ and $T_{c}^{\mathrm{Lyd}}$ is -4.9 and -1.9 , respectively. These results and Figures 2(a) and 2(b) show clearly that Joback technique underpredicts critical temperature, mostly for compounds which can be condensed onto particle phase, with high boiling temperature. The experimental group contributions provided by Lydersen are therefore more accurate than those provided by Joback. Thus, the Lydersen technique is more reliable than the Joback technique to estimate $T_{c}$.

Figure 3 shows $P_{c}^{\mathrm{Job}}$ and $P_{c}^{\mathrm{Lyd}}$ versus experimental values for a set of 117 compounds. The RMSE is $4.5 \mathrm{~atm}$ and $2.6 \mathrm{~atm}$ for Joback and Lydersen, respectively. According to Figures $3(\mathrm{a})$ and 3(b), $P_{c}$ estimated by Lydersen matches fairly better $\left(R^{2}=0.95\right)$ experimental data than $P_{c}$ estimated by Joback $\left(R^{2}=0.85\right)$. Joback technique considerably overpredicts critical pressure with $\mathrm{MBE}$ of $1,95 \mathrm{~K}$ higher than $0,39 \mathrm{~K}$ obtained with the Lydersen technique. In fact, besides group contribution, Lydersen technique takes into account molecular weight. Therefore, the Lydersen technique is retained to the critical pressure estimation in this paper. This is in agreement with Poling et al. [38] who found that the Lydersen technique is one of the best techniques for estimating critical properties. For the five vapor pressure estimation methods described previously, we will use estimated $T_{b}, T_{c}$, and $P_{c}$ because there is in general a lack of experimental data. 


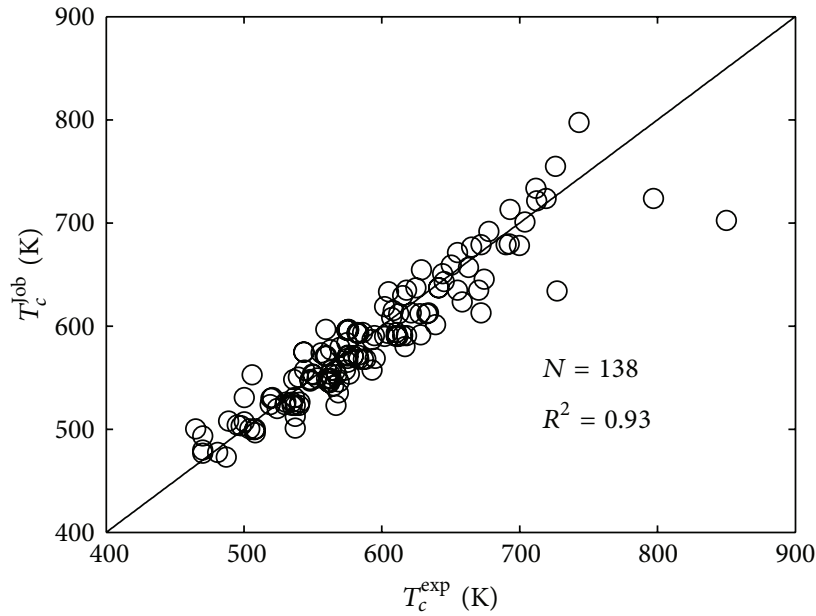

(a)

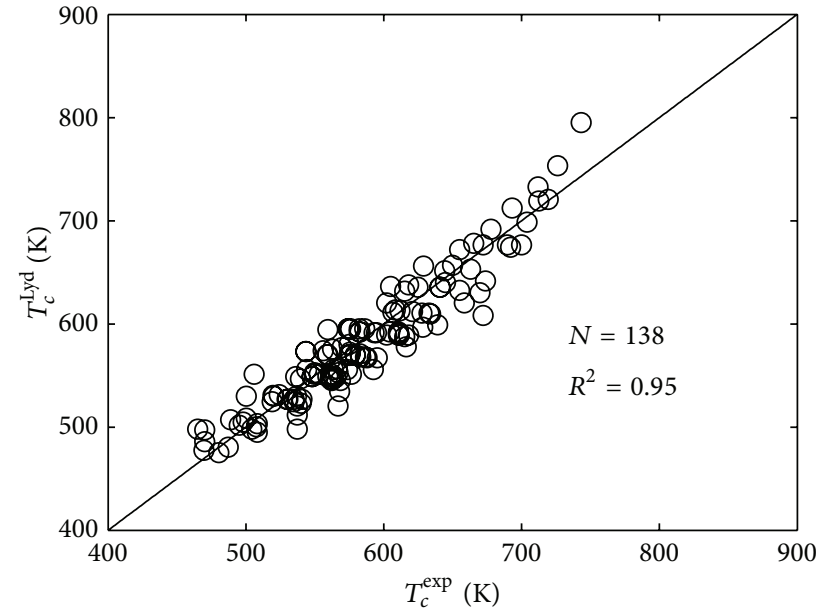

(b)

FIGURE 2: Estimated critical temperature for a set of 138 species versus experimental values for the (a) Joback technique and (b) Lydersen technique. The black line is the $1: 1$ diagonal.

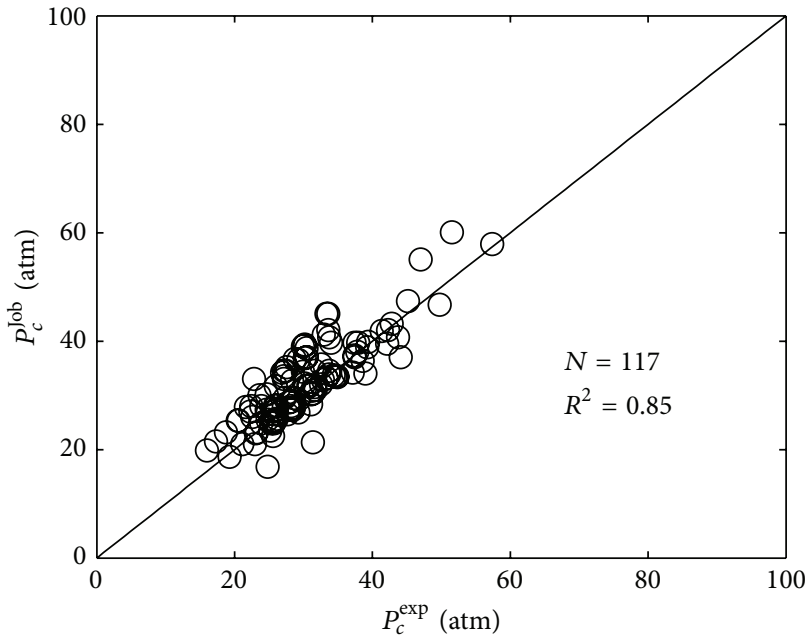

(a)

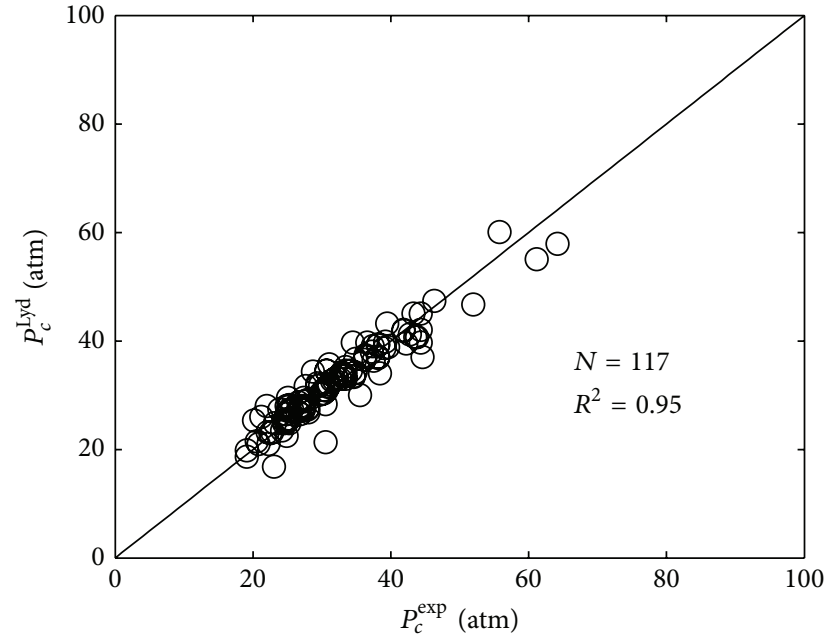

(b)

FIGURE 3: Estimated critical pressure for a set of 117 species versus experimental values for the (a) Joback technique and (b) Lydersen technique. The black line is the $1: 1$ diagonal.

Some of the five methods described in Section 2.3 need $P_{c}, T_{c}$, and $T_{b}$, while others need only $T_{c}$ and $T_{b}$. This last pure substance property is estimated by the Joback technique, and the two critical properties are estimated by the Lydersen technique.

3.2. Evaluation of Vapor Pressure Estimation Methods. The accuracy of each method is assessed in terms of the mean absolute error (MAE), the main bias error (MBE), and the root mean square error (RMSE) (Table 3). The MBE measures the average difference between the estimated and experimental values, while the MAE measures the average magnitude of the error. The RMSE also measures the error magnitude, but gives some greater weight to the larger errors. Their expressions are given by

$$
\begin{aligned}
\text { MBE } & =\frac{1}{N} \sum_{i=1}^{N}\left(\log P_{\text {est }, i}^{\mathrm{vap}}-\log P_{\text {exp }, i}^{\mathrm{vap}}\right), \\
\text { MAE } & =\frac{1}{N} \sum_{i=1}^{N}\left|\log P_{\text {est }, i}^{\mathrm{vap}}-\log P_{\mathrm{exp}, i}^{\mathrm{vap}}\right|, \\
\mathrm{RMSE} & =\sqrt{\frac{1}{N} \sum_{i=1}^{N}\left(\log P_{\mathrm{est}, i}^{\mathrm{vap}}-\log P_{\mathrm{exp}, i}^{\mathrm{vap}}\right)^{2} .}
\end{aligned}
$$


TABLE 2: MAE, MBE, and RMSE of vapor pressure computed based on various methods.

\begin{tabular}{lccccc}
\hline & GW & LK & mM & MY & 0.2652 \\
MAE & 0.3235 & 0.3240 & 0.3186 & 0.3013 \\
MBE & 0.0736 & -0.1513 & 0.0263 & 0.0270 & -0.0980 \\
RMSE & 0.4496 & 0.4909 & 0.4426 & 0.3811 & 0.4525 \\
\hline
\end{tabular}

TABLE 3: MAE, MBE, and RMSE of vapor pressure computed based on various methods for each class of compounds.

\begin{tabular}{|c|c|c|c|c|c|}
\hline & GW & LK & $\mathrm{mM}$ & MY & AW \\
\hline \multicolumn{6}{|c|}{ Hydrocarbons } \\
\hline MAE & 0.1455 & 0.1303 & 0.1424 & 0.1251 & 0.1384 \\
\hline MBE & 0.0547 & 0.0427 & 0.0486 & 0.0054 & 0.0603 \\
\hline RMSE & 0.1983 & 0.1750 & 0.1930 & 0.1711 & 0.1848 \\
\hline \multicolumn{6}{|c|}{ Monofunctionalized species } \\
\hline MAE & 0.3692 & 0.3168 & 0.1424 & 0.2699 & 0.2900 \\
\hline MBE & 0.0355 & -0.1712 & -0.0189 & -0.0402 & -0.1141 \\
\hline RMSE & 0.4992 & 0.4471 & 0.4955 & 0.3891 & 0.4130 \\
\hline \multicolumn{6}{|c|}{ Difunctionalized species } \\
\hline MAE & 0.4494 & 0.5641 & 0.4109 & 0.4291 & 0.5063 \\
\hline MBE & 0.2875 & -0.3322 & 0.2084 & 0.2378 & -0.2456 \\
\hline RMSE & 0.5506 & 0.6978 & 0.5120 & 0.5398 & 0.6291 \\
\hline \multicolumn{6}{|c|}{ Tri- and more functionalized species } \\
\hline MAE & 0.4407 & 0.5946 & 0.4596 & 0.4261 & 0.5489 \\
\hline MBE & 0.0536 & -0.3661 & -0.0339 & 0.1632 & -0.2739 \\
\hline RMSE & 0.5494 & 0.8386 & 0.5592 & 0.5065 & 0.7704 \\
\hline
\end{tabular}

In (20), $P_{\mathrm{est}, i}^{\mathrm{vap}}$ and $P_{\mathrm{exp}, i}^{\mathrm{vap}}$ are the estimated and experimental values of $\operatorname{VOC} i$, respectively, and $N$ is the total number of VOC. We have also used linear correlation coefficient which measures the degree of correspondence between the estimated and experimental distributions.

The logarithms of vapor pressures estimated at $T=$ $298 \mathrm{~K}$ for different methods are compared in the scatter plots shown in Figure 4 for a set of 262 VOC. Corresponding MAE, MBE, and RMSE are given in Table 1. In this figure, it is clear that all the five methods give similar scatter for vapor pressures higher than $10^{-5}$ atm. The species concerned are hydrocarbons (Figure 5). For the set of 28 tri- and more functionalized species used in this study, vapor pressures are lower than $10^{-2}$ atm (Figure 8).

Figure 4(d) shows that MY method is well correlated with experimental values. For this method, we have one of the best correlation coefficients $R^{2}=0.968$. This method shows no systematic bias for vapor pressure lower than $10^{-5}$ atm, while it is not the case for other methods. The MBE found here is 0.027. This value is one of the lowest ones of the total VOC (see Table 1). Thus, the MY method does not show any systematic bias. This method also provides the smallest values of MAE and RMSE (0.265 and 0.381 , resp.). These results are in agreement with those found by Camredon and Aumont [19] using Ambrose technique to estimate critical properties. It is also found that this method provides the smallest values of these errors for a set of 74 hydrocarbons (see Table 2). Those are compounds with vapor pressure higher than $10^{-2}$ atm.
This result is not the same for mono- and difunctionalized species whose errors are some of the largest ones. The vapor pressures higher than $10^{-4}$ atm are fairly well estimated. Using a set of 45 multifunctional compounds, Barley and McFiggans [21] found that MY method tends to overpredict vapor pressure of lower volatility compounds. Furthermore, it is important to note that MY method provides one of the poor results for difunctionalized VOC (see Table 2). Thus, for a set of 32 difunctionalized VOC, estimation values fit the experimental ones with a coefficient $R^{2}=0.957$ (Figure 7) which is the smallest value obtained for this class of species. Vapor pressures are overpredicted with a bias of 0.24 , while the RMSE $=0.54$ is of the same order of magnitude as those obtained by other methods. In contrast, Figure 8 shows that MY method has the best correlation for tri- and more functionalized species and is therefore the best method to estimate vapor pressure for this class of species. The systematic errors reported in Table 2 allow us to conclude that assumption. Indeed, the peculiarity of the MY method is that it takes into account the molecular structure.

Figure 4(c) displays the results for the mM method. This method gives one of the lowest scatterings with a coefficient $R^{2}=0.957$ and agrees with other methods for the highest vapor pressures. It shows a positive bias $(\mathrm{MBE}=0.026)$ for the total set of 262 VOC. As the GW method, the mM method tends to overpredict vapor pressures lower than $10^{-6}$ atm. Furthermore, these methods describe vaporisation entropy by taking into account van der Waals interactions. 


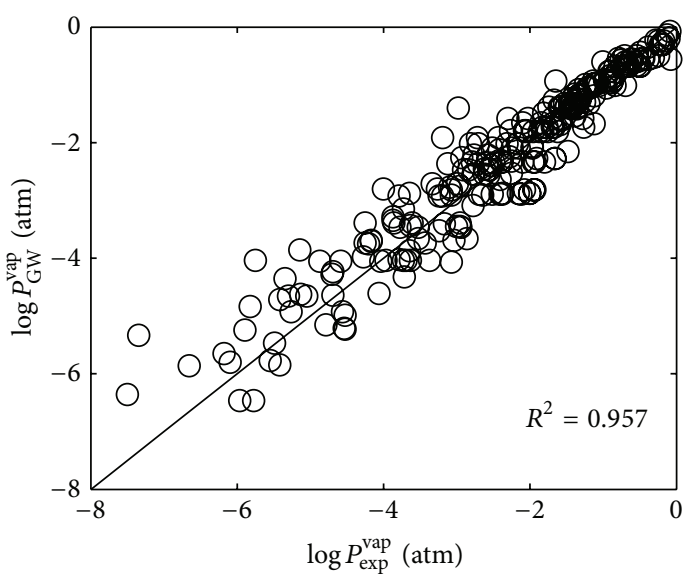

(a)

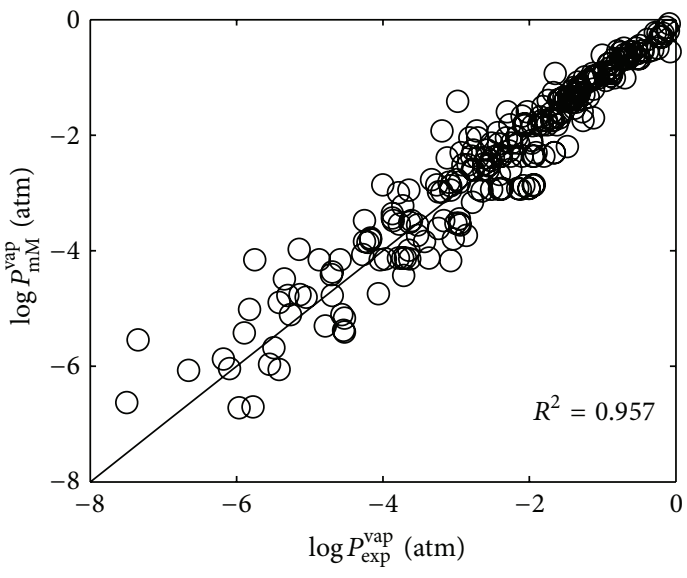

(c)

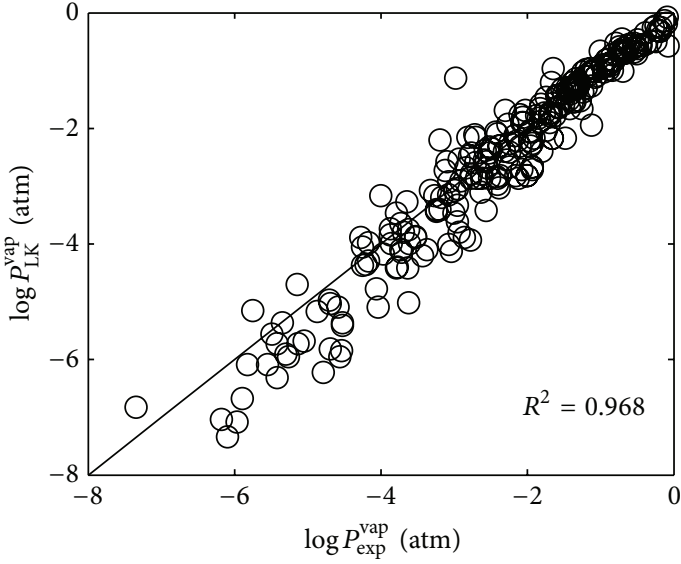

(b)

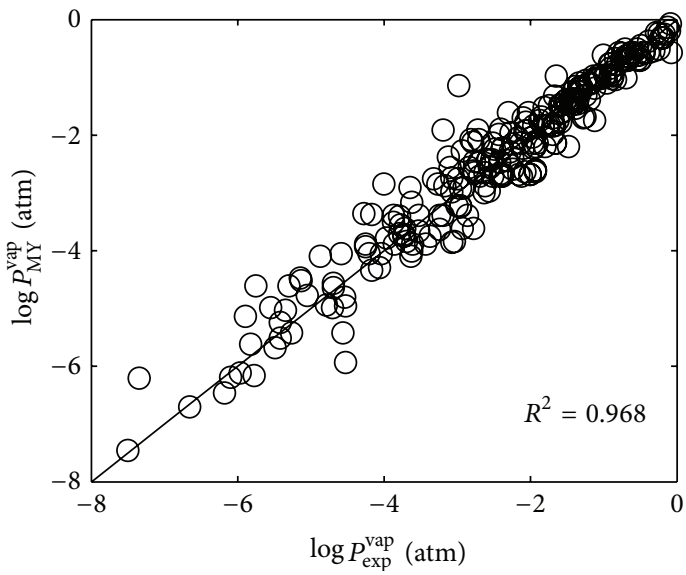

(d)

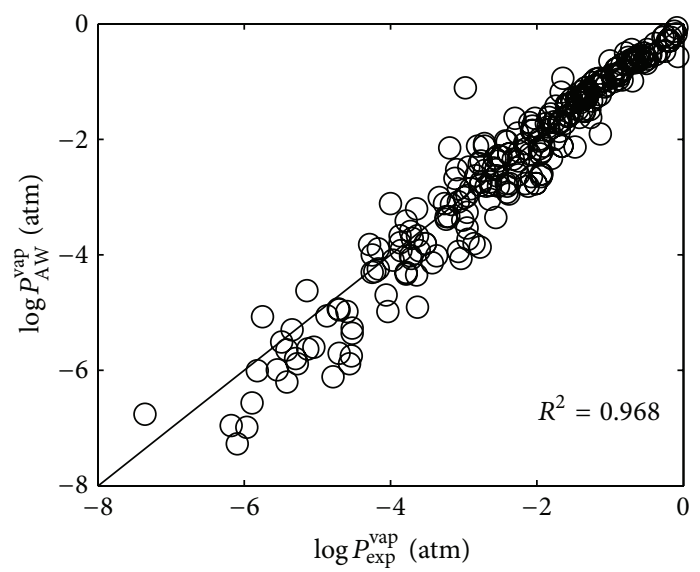

(e)

FIGURE 4: Logarithm of estimated vapor pressure of all VOCs used in this study versus experimental values for the (a) GW, (b) LK, (c) mM, (d) MY, and (e) AW methods. The black line is the 1:1 diagonal.

The root mean square error $(\mathrm{RMSE}=0.442)$ is close to those provided by GW and AW methods. The mM method is then less appropriate than the four others for all classes of VOC.

Figure 5(c) shows that the predicted values match the experimental values with a coefficient $R^{2}=0.96$ for 32 difunctionalized species. For this class of species, estimates are provided with a positive bias $(\mathrm{MBE}=0.208)$ and an RMSE of 0.512 . These are the best values obtained from all the five methods (see Table 2) for difunctionalized species. Thus, $\mathrm{mM}$ method is more accurate than others to estimate vapor pressure for difunctionalized species, but does not provide 


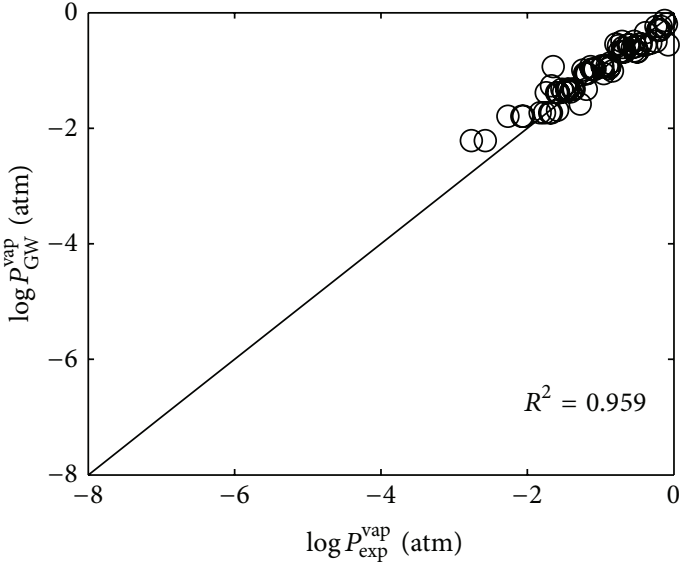

(a)

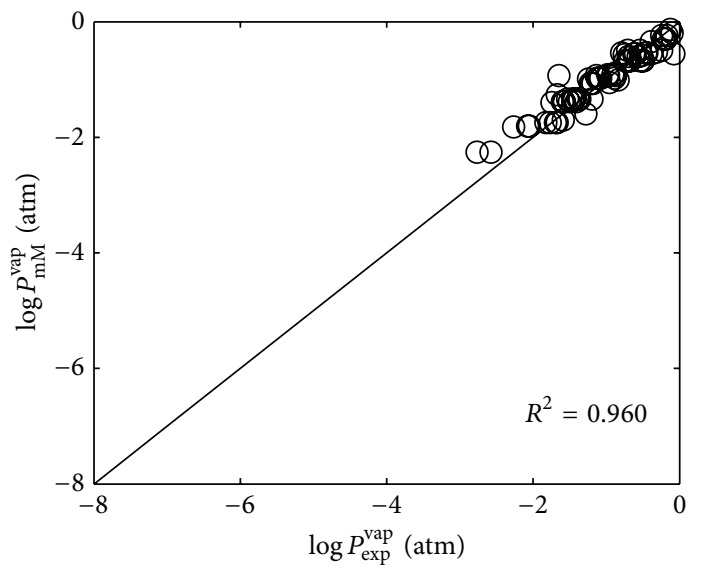

(c)

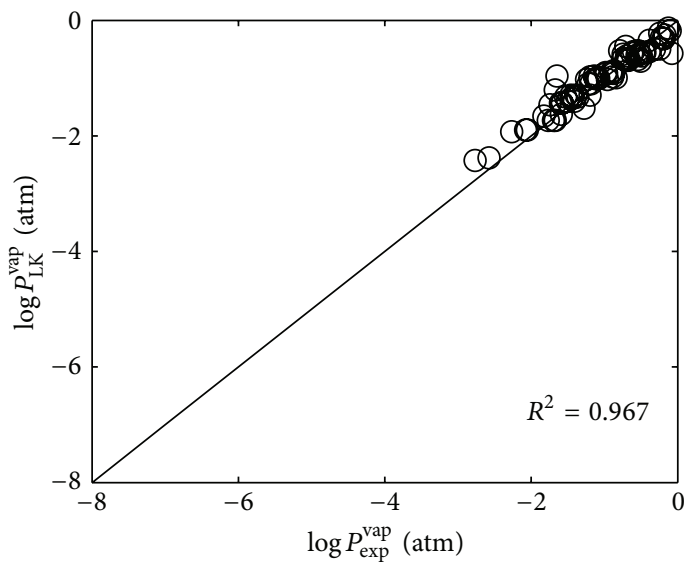

(b)

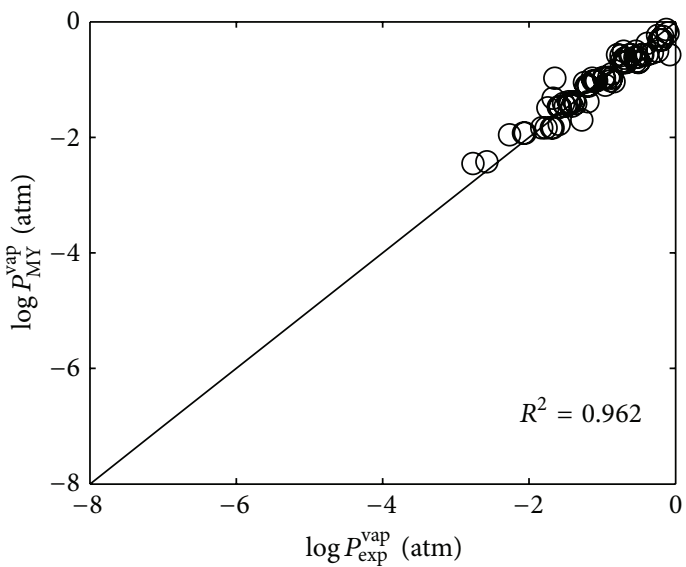

(d)

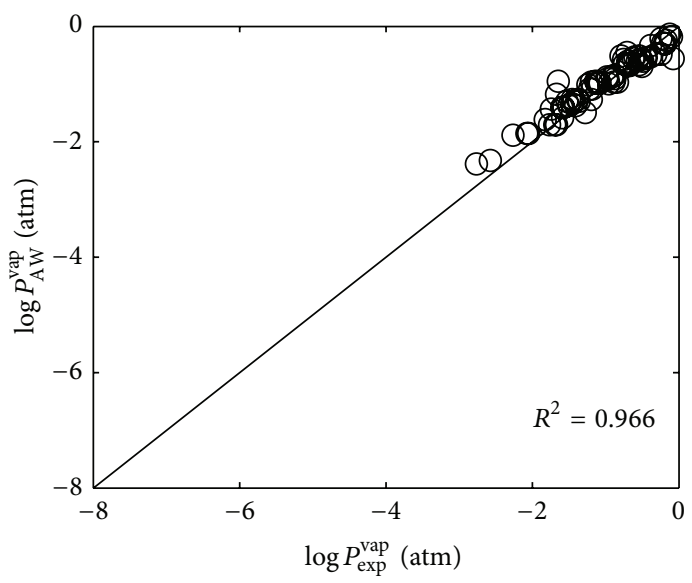

(e)

FIGURE 5: Logarithm of estimated vapor pressure for a set of 74 hydrocarbons versus experimental values for the (a) GW, (b) LK, (c) mM, (d) MY, and (e) AW methods. The black line is the 1:1 diagonal.

good results for monofunctionalized (Figure 3 ) and tri- and more functionalized species (Figure 5).

It can be seen in Figure 7 that estimated values provided by GW method are strongly correlated with experimental values $\left(R^{2}=0.960\right)$ for difunctionalized species. This method tends to overpredict vapor pressure for this class of species
$(\mathrm{MBE}=0.288)$, but does not show any bias for other classes of species (Table 2). Figure 8 shows that we have very acceptable results for tri- and more functionalized species with RMSE and MAE equal to 0.549 and 0.440 , respectively.

Except for tri- and more functionalized species (see Figure 8), it is clear from Figures 4 to 7 that the LK method 


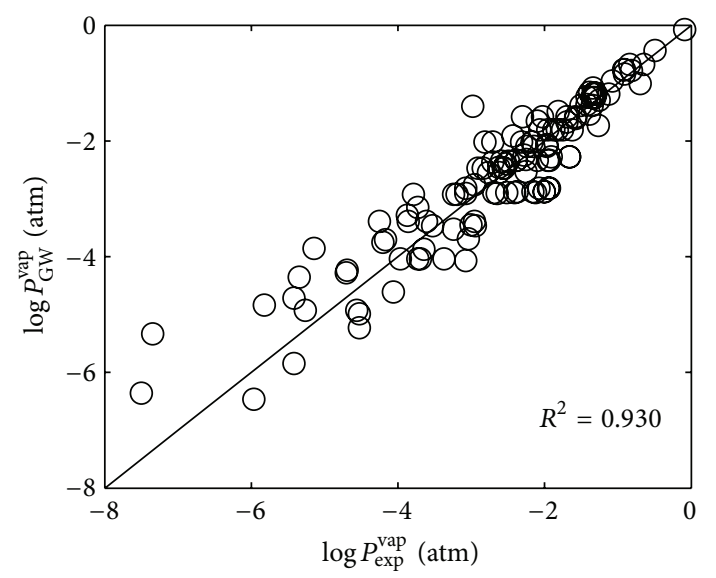

(a)

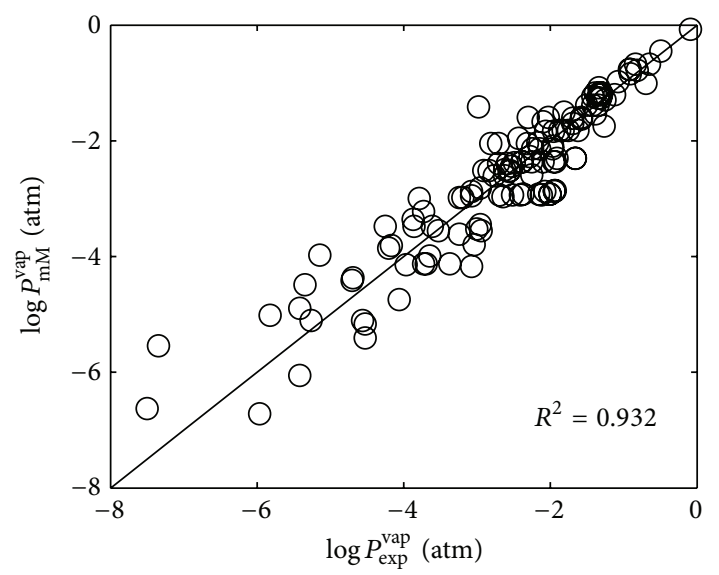

(c)

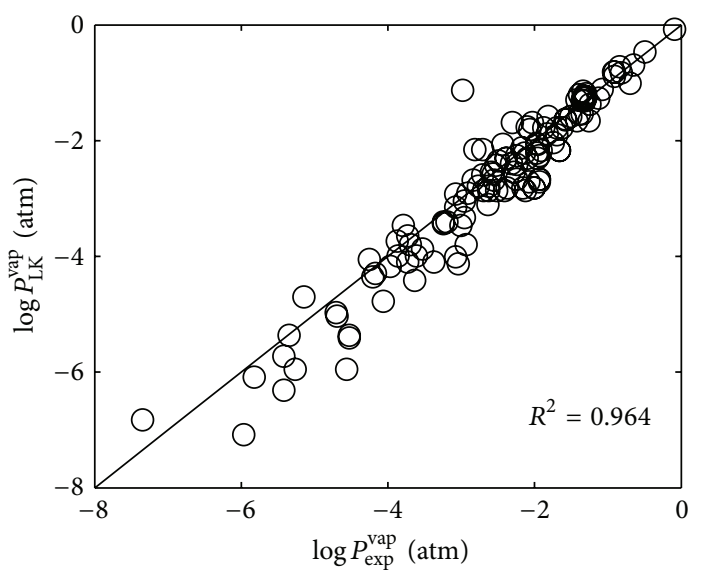

(b)

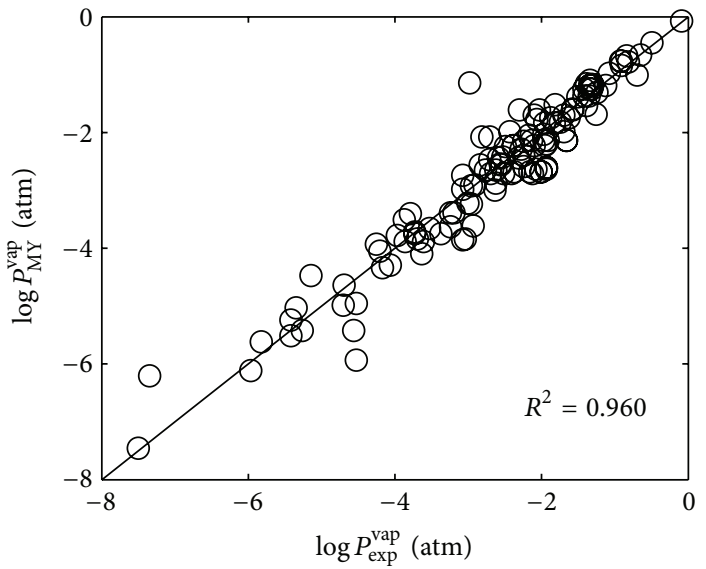

(d)

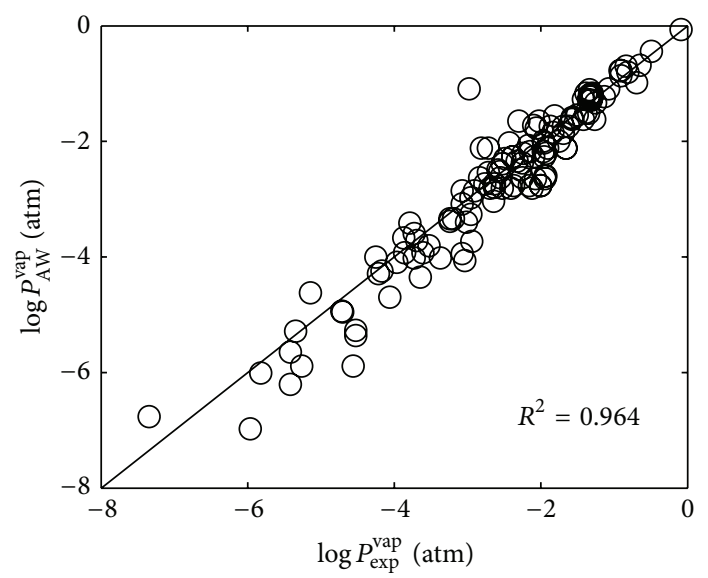

(e)

FIGURE 6: Logarithm of estimated vapor pressure for a set of 128 monofunctionalized species versus experimental values for the (a) GW, (b) LK, (c) mM, (d) MY, and (e) AW methods. The black line is the 1:1 diagonal.

gives accurate values, based upon best correlation coefficient values. This method is the second best one of the five methods, but it has the greatest systematic bias (RMSE = 0.490, $\mathrm{MAE}=0.32$ ) for the total set of VOC and for difunctionalized species $(\mathrm{RMSE}=0.70, \mathrm{MAE}=0.56)$. The MAE of hydrocarbons and monofunctionalized species are
0.142 and 0.36 , respectively. For these species, Figures 5 and 6 give the best correlations.

The AW and LK methods are both based on Antoine's equation. According to all figures plotted, it is clear that these two methods give very similar results. The peculiarity of AW is that, for the monofunctionalized compounds, 


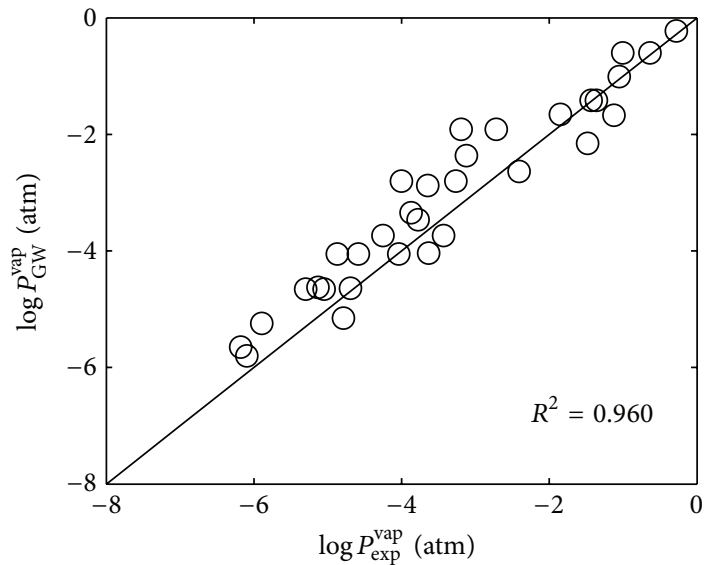

(a)

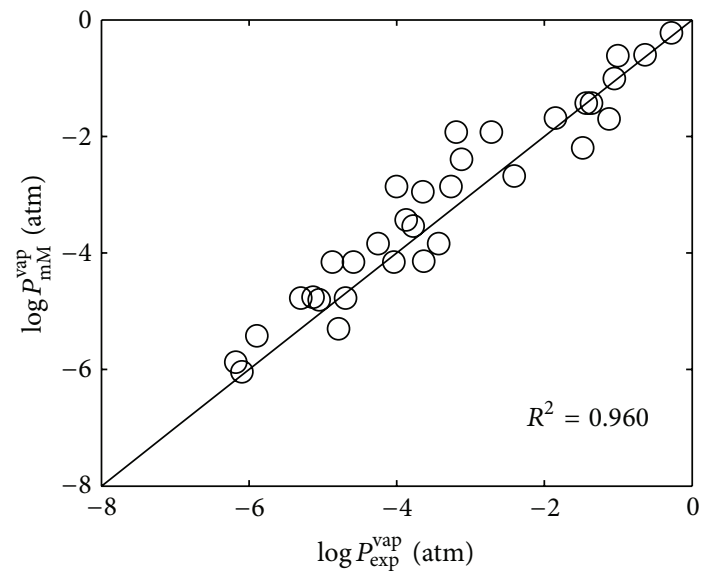

(c)

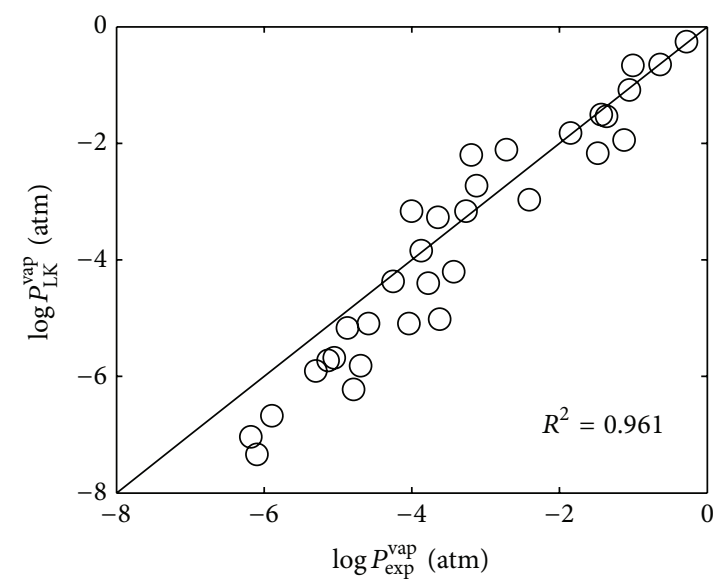

(b)

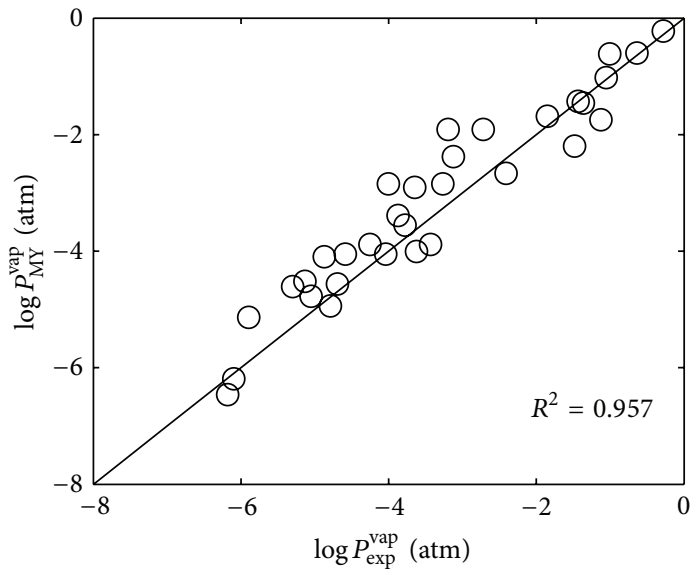

(d)

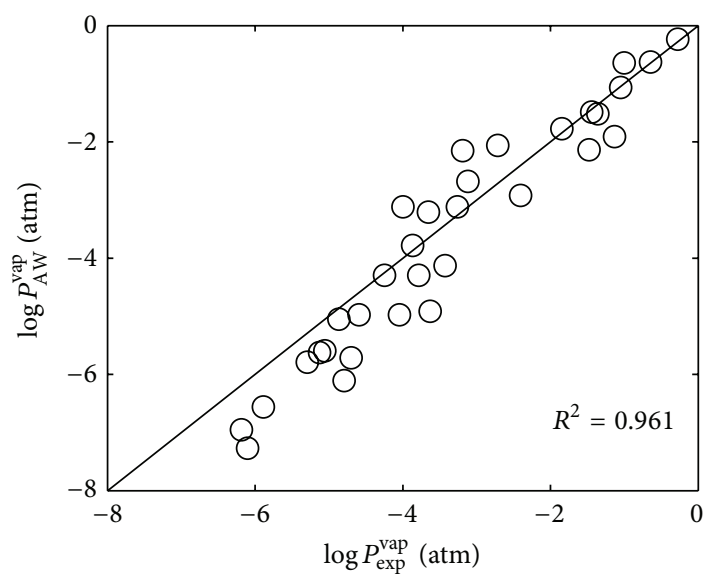

(e)

FIGURE 7: Logarithm of estimated vapor pressure for a set of 32 difunctionalized species versus experimental values for the (a) GW, (b) LK, (c) mM, (d) MY, and (e) AW methods. The black line is the 1:1 diagonal.

the predicted and experimental values are strongly correlated with a coefficient $R^{2}=0.9638$.

Vapor pressures for a set of 74 hydrocarbons are higher than $10^{-3} \mathrm{~atm}$. It is found for the five methods that estimated values for this class of species are well correlated (Figure 5).
Furthermore, vapor pressures of tri- and more functionalized species are below $10^{2}$ atm (Figure 8). For this class of species, LK method yields a weak correlation and has the largest positive bias. Therefore, this method is the least reliable to estimate vapor pressure for tri- and more functionalized species. 


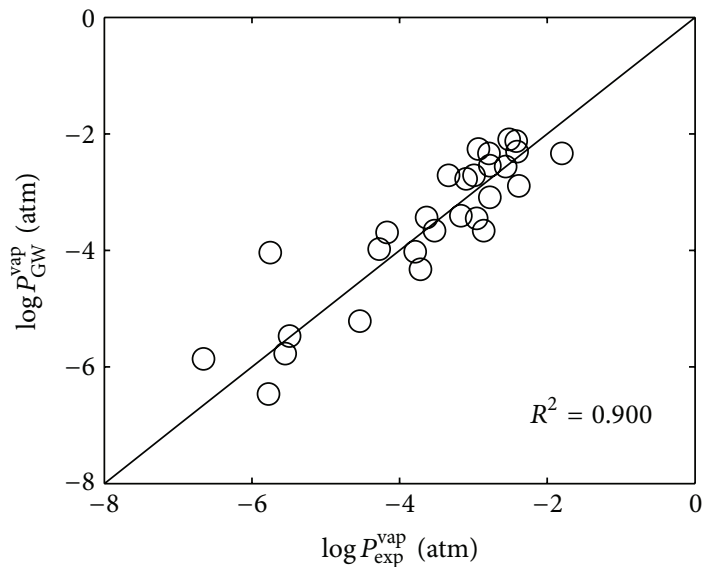

(a)

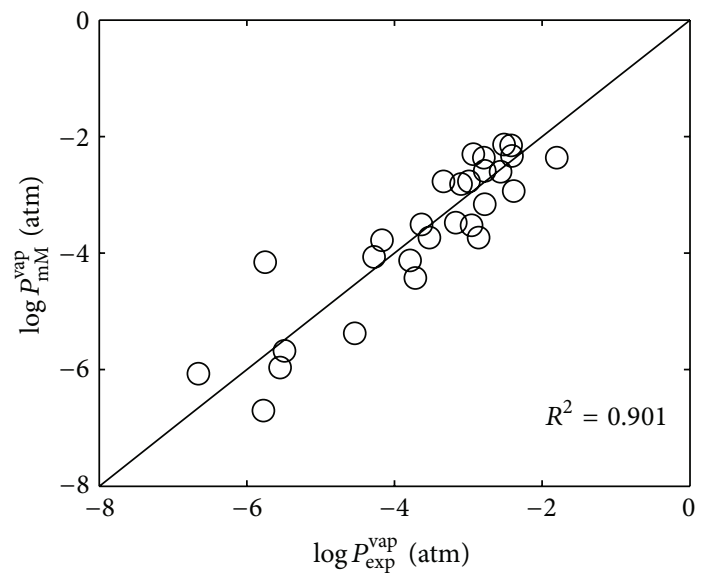

(c)

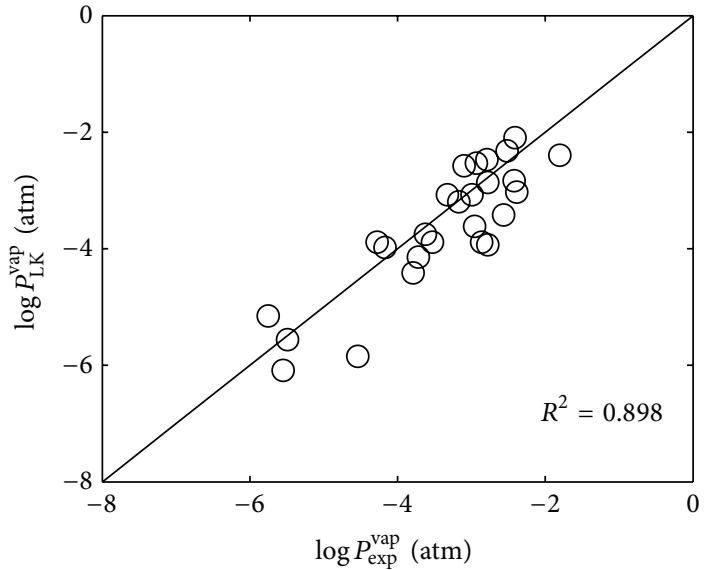

(b)

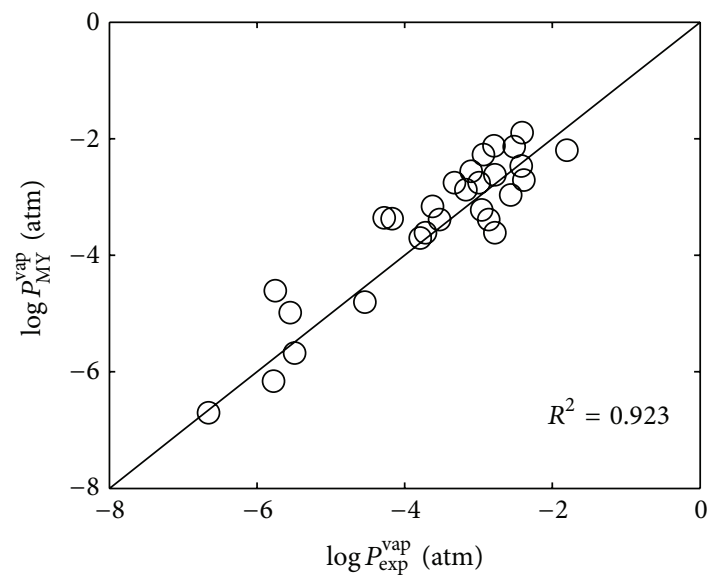

(d)

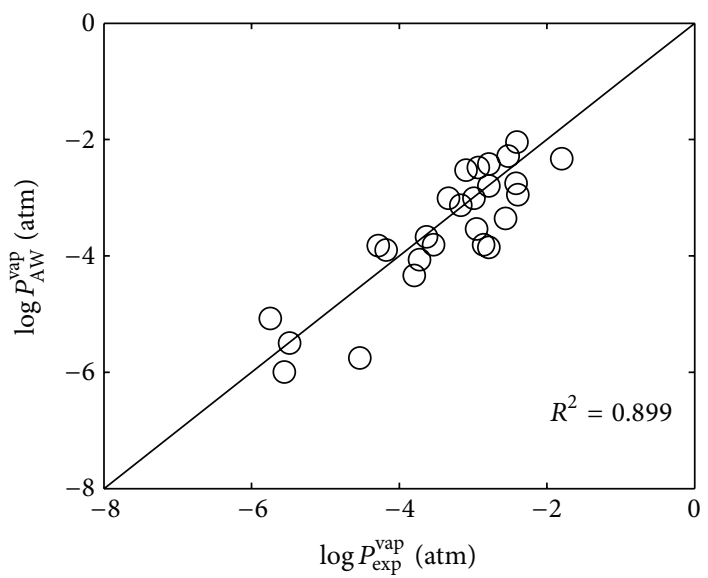

(e)

FIGURE 8: Logarithm of estimated vapor pressure for a set of 28 tri- and more functionalized species versus experimental values for the (a) GW, (b) LK, (c) mM, (d) MY, and (e) AW methods. The black line is the $1: 1$ diagonal.

\section{Conclusion}

We have evaluated in this study five vapor pressure estimation methods useful for simulating the dynamics of atmospheric organic aerosols. These are the Myrdal and Yalkovsky (MY), the Lee and Kesler (LK), the Grain-Watson (GW), the modified Mackay (mM), and the Ambrose-Walton (AW) methods. Some of them are based on the Antoine equation, while others are based on the extended form of the ClausiusClapeyron equation. But all of them take into account boiling 
temperature $T_{b}$ and (or) critical temperature $T_{c}$. Therefore, Joback technique has been used to estimate $T_{b}$, while the Lydersen technique was found to be better for $T_{c}$ estimation.

When using Joback to provide the $T_{b}$ values, LK, AW, and MY are the best three methods for all classes of species. Moreover, for a set of 262 volatile organic compounds and as illustrated in the scatter plots and errors computed, the MY method which appears to be the best one fails for difunctionalized species. For these latter species, the $\mathrm{mM}$ method provides good results, according to the correlation coefficient $R^{2}=0.960$ and the least errors reported in Table 2 . GW method is the least reliable, which provides the lowest results for all VOC and also for each class of species. Predictions made with the AW method for monofunctionalized species are more reliable than those made with the other four methods employing the Joback technique to provide the $T_{b}$. For vapor pressure higher than $10^{-2}$ atm, all the five methods give similar results.

This work highlights that the choice of a method to predict vapor pressure of volatile organic compounds depends on the number of functional groups existing in the species.

\section{References}

[1] J. Seinfeld and S. Pandis, Amospheric Chemestry and Physics: From a Pollution to Climate Change, John Wiley \& Sons, New York, NY, USA, 1998.

[2] M. Tombette, Modélisation des aérosols et de leurs propriãltés optiques sur l'Europe et l'île de France: validation, sensibilité et assimilation des données [Thèse], Ecole nationale des ponts et chaussées, 2007.

[3] P. Adams and J. Seinfeld, "Predicting global aerosol size distributions in general circulation models," Journal of Geophysical Research, vol. 107, no. 19, pp. AAC 4-1-AAC 4-23, 2002.

[4] S. Gons, L. A. Barrie, J. P. Blanchet et al., "Canadian aerosols module: a size-segregated simulation of atmospheric aerosol processes for climate to and air quality models. I Module development," Journal of Geophysical Research, vol. 108, no. 1, pp. AAC 3-1-AAC 3-16, 2003.

[5] E. R. Whitby and P. H. McMurry, "Modal aerosol dynamics modeling," Aerosol Science and Technology, vol. 27, no. 6, pp. 673-688, 1997.

[6] E. Debry, Modélisation et simulation de la dynamique des aérosols atmosphériques [Thèse], Ecole nationale des ponts et chaussées, 2004.

[7] B. Dahneke, Theory of Dispersed Multiphase Flow, Academic press, New York, NY, USA, 1983.

[8] E. Debry, K. Fahey, K. Sartelet, B. Sportisse, and M. Tombette, "Technical note: a new SIze REsolved Aerosol Model (SIREAM)," Atmospheric Chemistry and Physics, vol. 7, no. 6, pp. 1537-1547, 2007.

[9] C. Tong, M. Blanco, W. A. Goddard III, and J. H. Seinfeld, "Thermodynamic properties of multifunctional oxygenates in atmospheric aerosols from quantum mechanics and molecular dynamics: dicarboxylic acids," Environmental Science and Technology, vol. 38, no. 14, pp. 3941-3949, 2004.

[10] T. Banerjee, M. K. Singh, and A. Khanna, "Prediction of binary VLE for imidazolium based ionic liquid systems using COSMO-RS," Industrial and Engineering Chemistry Research, vol. 45, no. 9, pp. 3207-3219, 2006.
[11] M. Diedenhofen, A. Klamt, K. Marsh, and A. Schäfer, "Prediction of the vapor pressure and vaporization enthalpy of 1-nalkyl-3-methylimidazolium-bis-(trifluoromethanesulfonyl) amide ionic liquids," Physical Chemistry Chemical Physics, vol. 9, no. 33, pp. 4653-4656, 2007.

[12] P. B. Myrdal and S. H. Yalkowsky, "Estimating pure component vapor pressures of complex organic molecules," Industrial and Engineering Chemistry Research, vol. 36, no. 6, pp. 2494-2499, 1997.

[13] R. J. Griffin, K. Nguyen, D. Dabdub, and J. H. Seinfeld, "A coupled hydrophobic-hydrophilic model for predicting secondary organic aerosol formation," Journal of Atmospheric Chemistry, vol. 44, no. 2, pp. 171-190, 2003.

[14] B. K. Pun, R. J. Griffin, C. Seigneur, and J. H. Seinfeld, "Secondary organic aerosol 2. Thermodynamic model for gas/ particle partitioning of molecular constituents," Journal of Geophysical Research D, vol. 107, no. 17, pp. AAC 4-1-AAC 4-15, 2002.

[15] M. E. Jenkin, "Modelling the formation and composition of secondary organic aerosol from $\alpha$ - and $\beta$-pinene ozonolysis using MCM v3," Atmospheric Chemistry and Physics, vol. 4, no. 7, pp. 1741-1757, 2004.

[16] D. Mackay, A. Bobra, D. W. Chan, and W. Y. Shiu, "Vapor pressure correlations for low-volatility environmental chemicals," Environmental Science and Technology, vol. 16, no. 10, pp. 645649, 1982.

[17] J. F. Pankow and W. E. Asher, "SIMPOL.1: a simple group contribution method for predicting vapor pressures and enthalpies of vaporization of multifunctional organic compounds," Atmospheric Chemistry and Physics, vol. 8, no. 10, pp. 2773-2796, 2008.

[18] M. Capouet and J.-F. Müller, "A group contribution method for estimating the vapour pressures of $\alpha$-pinene oxidation products," Atmospheric Chemistry and Physics, vol. 6, no. 6, pp. $1455-1467,2006$.

[19] M. Camredon and B. Aumont, "Assessment of vapor pressure estimation methods for secondary organic aerosol modeling," Atmospheric Environment, vol. 40, no. 12, pp. 2105-2116, 2006.

[20] S. Compernolle, K. Ceulemans, and J.-F. Müller, “Technical Note: vapor pressure estimation methods applied to secondary organic aerosol constituents from $\alpha$-pinene oxidation: an intercomparison study," Atmospheric Chemistry and Physics, vol. 10, no. 13, pp. 6271-6282, 2010.

[21] M. H. Barley and G. McFiggans, "The critical assessment of vapour pressure estimation methods for use in modelling the formation of atmospheric organic aerosol," Atmospheric Chemistry and Physics, vol. 10, no. 2, pp. 749-767, 2010.

[22] L. E. Yu, M. L. Shulman, R. Kopperud, and L. M. Hildemann, "Characterization of organic compounds collected during Southeastern Aerosol and Visibility Study: water-soluble organic species," Environmental Science and Technology, vol. 39, no. 3, pp. 707-715, 2005.

[23] M. Jang and R. M. Kamens, "Characterization of secondary aerosol from the photooxidation of toluene in the presence of NOx and 1-propene," Environmental Science and Technology, vol. 35, no. 18, pp. 3626-3639, 2001.

[24] W. E. Asher, J. F. Pankow, G. B. Erdakos, and J. H. Seinfeld, "Estimating the vapor pressures of multi-functional oxygencontaining organic compounds using group contribution methods," Atmospheric Environment, vol. 36, no. 9, pp. 1483-1498, 2002. 
[25] D. R. Lide, Handbook of Chemistry and Physics, 86th edition, 1997.

[26] C. L. Yams, Hanbook of Vapour Pressure, Vols. 2 and 3, Guef Publishing Compagny, Houston, Tex, USA, 1994.

[27] T. Boulik, V. Freid, and E. Hala, The Vapour Pressure of Pure Substances, Elsevier, Amsterdam, The Netherlands, 1984.

[28] K. J. Joback and R. C. Reid, "Estimation of pure component properties from group contribution," Chemical Engineering Communications, vol. 57, pp. 233-243, 1987.

[29] P. W. Bruckmann and H. Willner, "Infrared spectroscopic study of peroxyacetyl nitrate (PAN) and its decomposition products," Environmental Science and Technology, vol. 17, no. 6, pp. 352-357, 1983.

[30] Y. Nannoolal, Development and critical evaluation of group contribution methods for the estimation of critical properties, liquid vapour pressure and liquid viscosity of organic compounds [Ph.D. thesis], University of Kwazulu Natal, 2006.

[31] P. B. Myrdal, J. F. Krzyzaniak, and S. H. Yalkowsky, "Modified Trouton's rule for predicting the entropy of boiling," Industrial and Engineering Chemistry Research, vol. 35, no. 5, pp. 17881792, 1996.

[32] J. Vidal, Thermodynamique: Application au Génie Chimique et Ãa l'industrie du Pétrolière, Technip, Paris, Farnce, 1997.

[33] E. J. Baum, Chemical Property Estimation-Theory and Application, section 6.3, Lewis, Boca Raton, Fla, USA, 1998.

[34] R. P. Schwarzenbasch, P. M. Gschwend, and D. M. Imboden, Environmental Organic Chemistry, John Wiley \& Sons, New York, NY, USA, 2nd edition, 2003.

[35] W. J. Lyman, Environmental Exposure from Chemicals, vol. 1, chapter 2, CRC Press, Boca Raton, Fla, USA, 1985.

[36] S. H. Fishtine, "Reliable latent heats of vaporization," Environmental Science \& Technology, vol. 55, pp. 47-56, 1963.

[37] C. F. Grain, "Vapor pressure," in Handbook of Chemical Property Estimation Methods, chapter 14, McGraw-Hill, New York, NY, USA, 1982.

[38] B. E. Poling, J. M. Prausnitz, and J. P. O’Connell, The Properties of Gases and Iquids, McGraw-Hill, New York, NY, USA, 5th edition, 2001.

[39] R. C. Reid, J. M. Prausnitz, and B. E. Poling, The Properties of Gases and Liquids, McGraw-Hill, New York, NY, USA, 4th edition, 1986.

[40] D. Ambrose and J. Walton, "Vapor pressures up to their critical temperatures of normal alkanes and 1-alkohols," Pure and Applied Chemistry, vol. 61, pp. 1395-1403, 1989. 

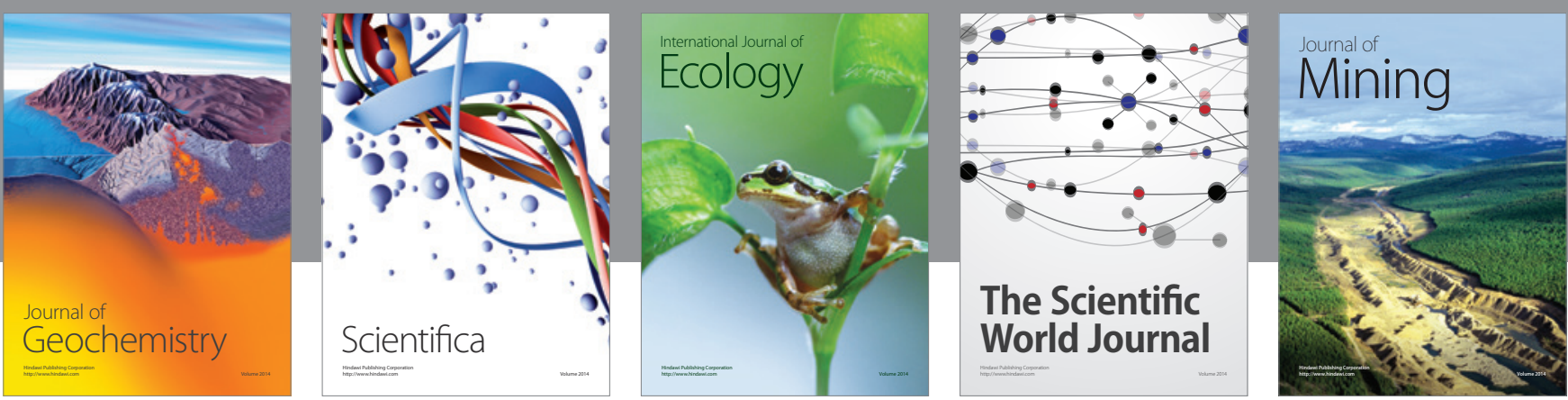

The Scientific World Journal
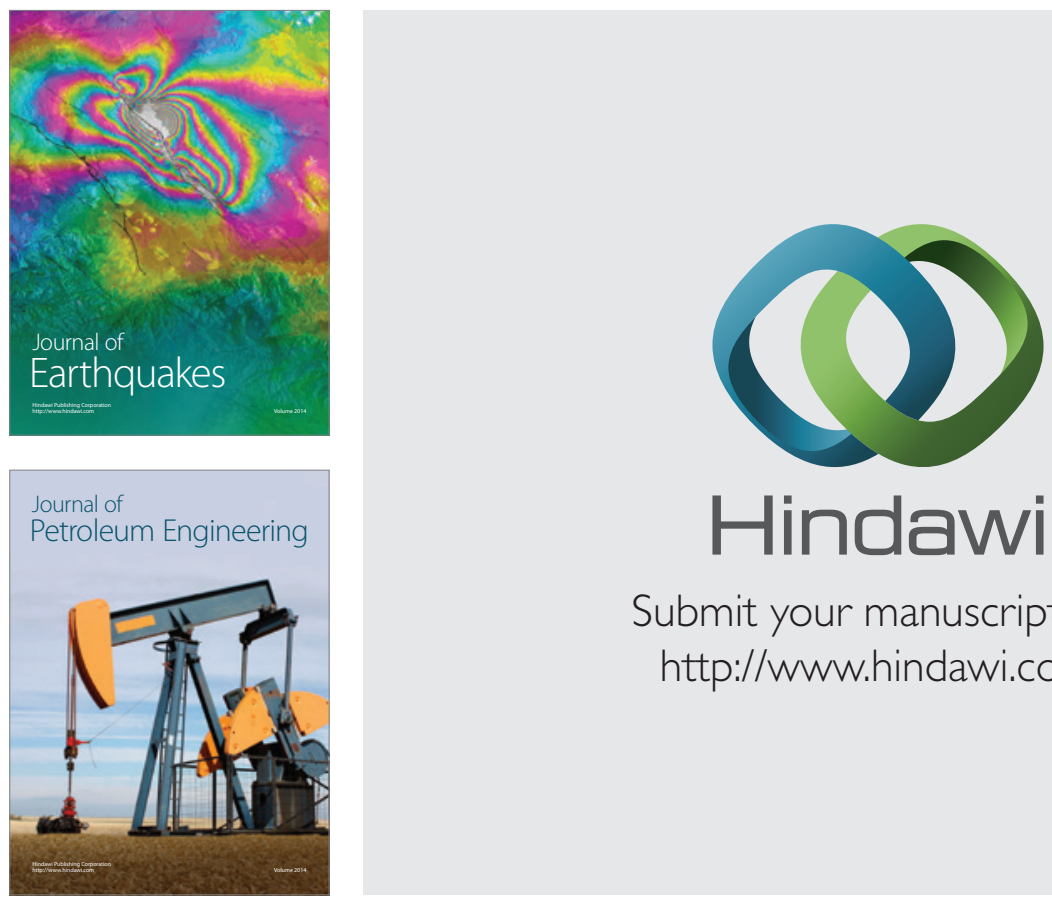

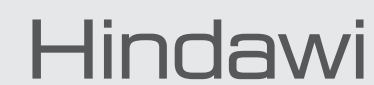

Submit your manuscripts at

http://www.hindawi.com
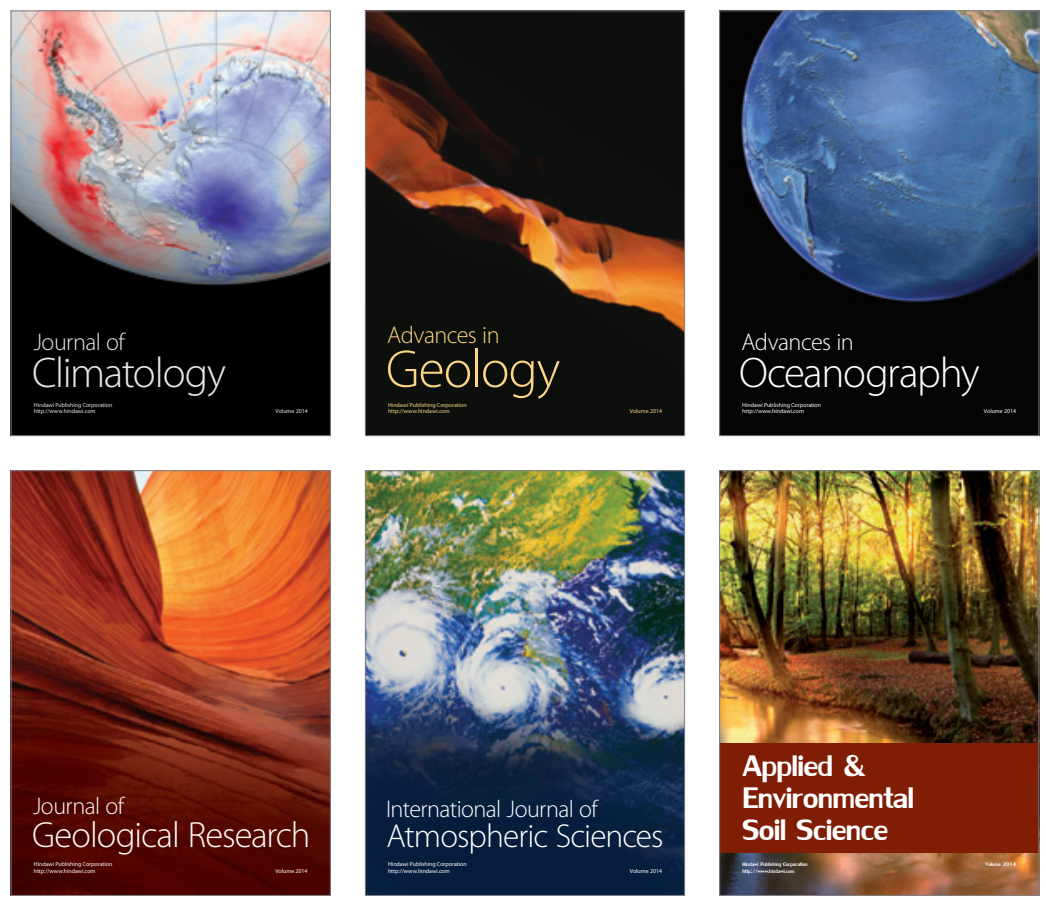
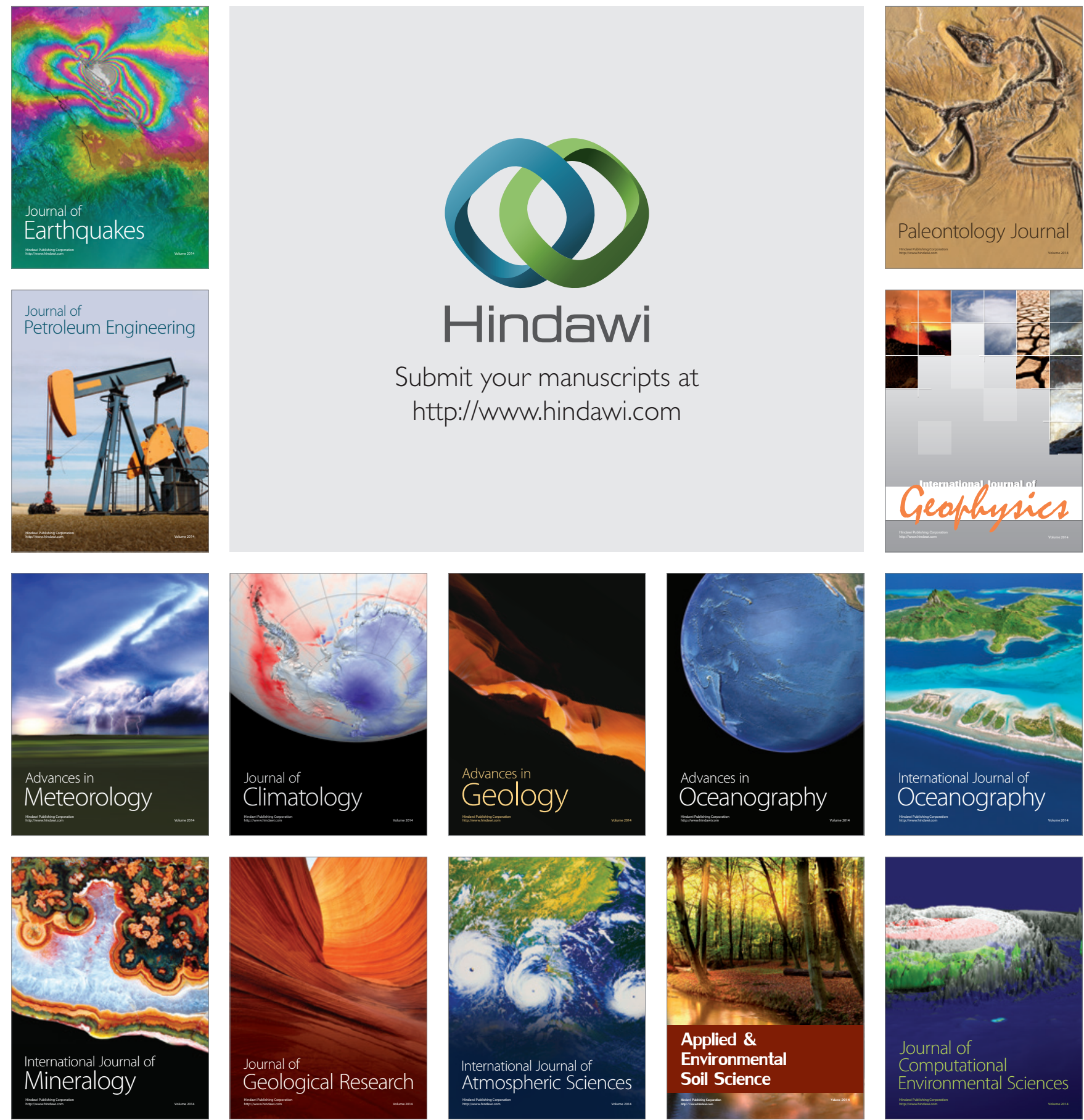